\title{
Is Chinese Run-on Sentence an Exception to the Iconicity of Sequence?
}

\author{
Xiao Chen
}

Correspondence: Xiao Chen, School of Foreign Languages, Zhejiang University of Finance and Economics, No. 18 Xueyuan Street, Xiasha Higher Education Zone, Hangzhou, Zhejiang, P.R. China.

Received: June 6, 2021

doi:10.5430/elr.v10n3p41
Accepted: July 21, $2021 \quad$ Online Published: July 22, 2021

URL: https://doi.org/10.5430/elr.v10n3p41

\begin{abstract}
As one of the most active scholars in the field of Chinese run-on sentence (CRS for short), Wang and Zhao (2016) keenly realize that CRS displays distinctive traits of spatiality, namely, chunkiness, discreteness and reversibility, among which, the last trait and the iconicity of sequence/order (e.g. Haiman, 1984, 1985) seem to depict a diametrically opposite picture. In the present article, there would be an attempt to undertake an investigation of Wang, Zhao et al.'s 'reversibility' to see whether or not CRS is an exception to the iconicity of sequence/order. The main arguments are as follows. First, 'reversibility' is borne out to be local by some linguistic facts, especially in: (i) duyuju within CRS; and (ii) shuncheng CRS. Second, although the 'reversibility' sometimes exhibits a tendency to change the positions of clauses/syntagms in CRS, there is a clear correlation between the clause order of CRS and iconicity. The sequence/order principle in practice emerges as a cognitive mechanism emitting some effects in the clause order of CRS. Third, the Reversibility Condition is required to come into being so as to arrive at a detailed specification of the applicable scope of the 'reversibility'. And finally, it is more preferable to ameliorate the spatiality of CRS as two traits, that is, chunkiness and discreteness.
\end{abstract}

Keywords: run-on sentences, reversibility, iconicity of sequence, duyuju, shuncheng CRS

\section{Introduction}

Chinese Run-on Sentence (CRS hereafter), being ruled out in (written) English grammar, appears to be a kind of unique phenomenon in Mandarin Chinese. This term is firstly thrust into the limelight by Lü (1979:27), who defines it as a kind of sentence where clauses follow one after another, and in many places they can be connected or simply cut. Meanwhile, in Lü's (1979:22) deliberation, CRS is overwhelmingly frequent in spoken Chinese (see also in Lian, 1992; Shen, 2012). The two eye-catching viewpoints of Lü (1979) mark the commence of CRS's detailed researches over the ensuing decades. The working definition of CRS, for instance, has experienced several upgrades (Gao, 1988; Wu \& Liang, 1992; Yuan, 2000; Zhang, 2000; Guo, 2004; Shen, 2004; Shen, 2012; Zhang, 2015; Sheng, 2016; Wang \& Zhao, 2016; Chen \& Duan, 2020), which can be encapsulated as follows: Chinese sentences, different from the Indo-European language family, "usually take a chronicle style" (Lian, 1993:67), and CRS is always treated as "a mirror of some typical features of Chinese" (Wu \& Liang, 1992:316). Since connective words are not absolute, CRS is often a composition of a cluster of juxtaposed phrasal and clausal expressions that share a peculiarity of "referentiality" (e.g. Shen, 2012). The co-occurrence of phrasal syntagms and clausal syntagms, the loose structure, and "the blurry line between main and subordinate clauses as well as between subjects and predicates" (Lian, 1992:4; Kong, 1997:283) are all results of the absence of explicit markings and structural representations of such running sentence. Consider the sentence:

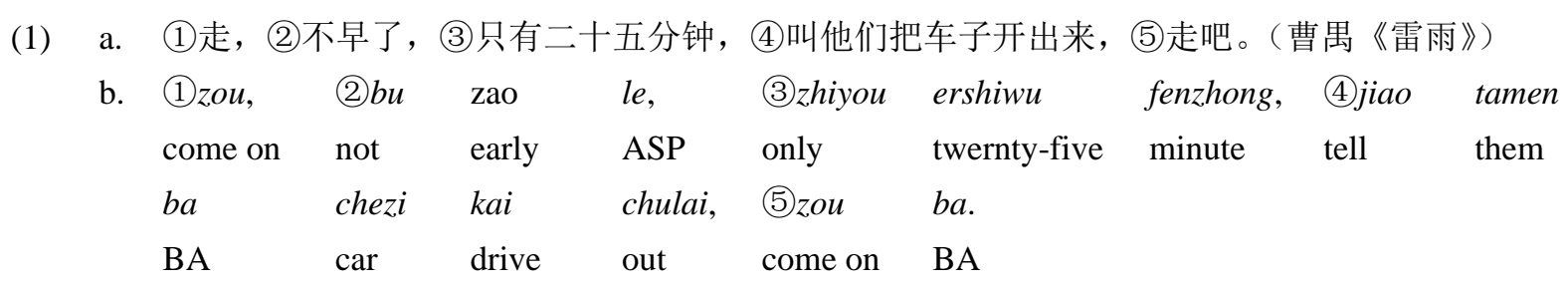

(From Thunderstorm by Cao Yu)

c. 'Come on. We haven't got much time. Only twenty-five minutes before the train goes. Tell them to get the car out. Come on'.

The sentence (1) contains five independent syntagms with no explicit connectives, rendering a loose structure. As 
well as being unique, all syntagms in such diffuse construction are shown as having no full subject or predicate. Namely, the dominant ingredient of the CRS in (1) is proved to be an incomplete subject-predicate construction, or namely, minor sentence ${ }^{1}$ (Chao, 1968; Shen, 2012). Furthermore, note that the subjects of some syntagms like (1), (3), (4) and (5) are not clearly specified. It means that the ambiguity of subject reference is borne out to be a "habitual frequenter" in CRS.

In central papers such as Hu \& Jin (1989), Wu \& Liang (1992) and Shen (2012), much efforts to provide an explicit characterization of CRS's structural properties are already underway. More recently, some illustrious works with regard to CRS tend to be spatiality-oriented in the footstep of Wang and Zhao (2016), who are keenly aware of the fact that the construction of CCS is marked by three spatial traits, namely, chunkiness, discreteness and reversibility, among which, 'reversibility' underlies that clauses/syntagms in a sentence is organized in a such flexible way that they can be moved to different positions, and even reversed in their positions (e.g. Wang \& Zhao, 2016; Wang \& Liu, 2021). However, the view of this kind of reversed clause order seems to display an opposite behavior with the "iconicity of sequence/order" (e.g. Haiman, 1980, 1984, 1985). Therefore, on the basis of acknowledging Wang et al.'s discreteness and chunkiness, the purpose of this study is to investigate the rationale of 'reversibility' so as to see whether or not CRS is an exception to the iconicity of sequence/order. For this examination, the present author will firstly zero in on some contexts where the use of 'reversibility' is ruled out. Then, pages are devoted to further discuss the sequential order principles on CRS and provide some constraints on the appearance of 'reversibility' inside CRS.

\subsection{Wang et al. 's Spatiality}

Early research endeavors (Hu \& Jin, 1989; Wu \& Liang, 1992; Wang, 1994; Zhang, 2000; Shen, 2012; Zhang, 2015; Sheng, 2016) have been absorbed in an inspection of CRS's structural properties.

In the same vein, based upon an inventive viewpoint that Chinese is a spatiality-dominant language, Wang and Zhao (2016) keenly realize that CRS, "as a mirror of Mandarin Chinese (Wu \& Liang, 1992:316)", also turns out to be spatiality-oriented. Therefore, Wang, Zhao et al. (e.g. Wang \& Zhao, 2016, 2017a, 2017b, 2017c, 2020; Cui, 2017; Cui \& Wang, 2019; Wang \& Liu, 2021), with zeal and genius, pursue the cognizance that the construction of CRS is marked by chunkiness, discreteness and reversibility, among which the 'chunkiness' is in essence about the same with 'juxtaposition" ${ }^{2}$ given by Shen (e.g. 2012). In general, they share a firm belief that a stream of syntagms (/full sentences and minor sentences), in default of explicit associative words, are loosely strung together, or juxtaposed, giving rise to the second spatial trait, 'discreteness'. This property, together with the 'fragmentability ${ }^{3}$, , is reserved to describe the absence of cohesive devices such as connectives among different linguistic units (Wang \& Liu, 2021:5), leading to the co-occurrence of phrasal and clausal syntagms, the loose structure, and ambiguity of subject reference (Wang \& Zhao, 2016, 2017a, 2017c, 2020; Cui, 2017; Wang \& Liu, 2021). Something to also note is that it is difficult to pinpoint the full or null subjects among syntagms.

Furthermore, with the mutual effect of 'chunkiness' and 'discreteness', the 'reversibility' of CRS comes in (Wang \& Zhao, 2016:18-19). In Wang and Zhao's (e.g. 2016) shrewd cognizance of 'reversibility', syntagms (/clauses and phrasal expressions) in CRS are organized in such a flexible way that they can be moved to different positions, and even reversed in their positions,-without any shift in meaning. This is hinted in example (2) from Wang and Zhao (2016:20).

(2) a. (1)到次日初八，(2)一顶轿子，(3)四个灯笼，(4)妇人换了一身艳色衣服，(5)王婆送亲，(6)玳安跟轿， (7)把妇人抬到家中来。(《金瓶梅》)

\footnotetext{
1 According to Chao (1968:83), sentences can be classified into full and minor sentences. The former consists of two parts, a subject and a predicate, while the latter usually is not in the subject-predicate form and occurs more often in oral speech, such as commands, vocatives, responses and exclamations. Moreover, Chao (1968:83) points out that, compared to the complete construction of a full sentence, most minor sentences are either verbal expressions or nominal expressions.

2 In Shen's (e.g. 2012, 2017, 2019) a series of landmark publications, 'juxtaposition', as a defining property of CRS, often depicts a fact that CRS is a string of 'minor sentences' (Chao, 1968) and full sentences without the presence of obvious connectives.

${ }^{3}$ In the words of Wang and Liu (2021:5), 'fragmentability' is closely germane to the 'discreteness'. Basically, it, due to the lack of explicit lingkages, between different clauses, refers to the greater flexibility in the organization of linguistic units.
} 
ciri chuba,

(2)yi-ding jiaozi,

(3)si-ge denglong,

(4) furen

until

huan-le

next day

eighth day

one-CL

sedan

four-CL

lantern

woman

change-ASP

yifu,

(5) wangpo

song

qin,

(6) dai-an

genjiao,

(7) $b a$

bright

clothes

Wangpo(name)

escort

wedding

Dai-an(name)

follow sedan BA

furen

tai

dao

jia

zhong

lai.

(From The Plum in the Golden Vase)

home

inside

come

c. 'The next day, in a single sedan chair, accompanied by four lanterns and escorted by Dame Wang and Taian, he had the woman carried off to his home'. (Translated by David Tod Roy)

d. (1)到次日初八, (4)妇人换了一身艳色衣服, (6)玳安跟轿, (5)王婆送亲, (3)四个灯笼, (2)一顶轿子, (7)把妇人抬到家中来。

e. (1)到次日初八，(6)玳安跟轿，(5)王婆送亲，(4)妇人换了一身艳色衣服，(2)一顶轿子，(3)四个灯笼， (7)把妇人抬到家中来。

What is worthy of special mention is that there is no bright-line distinction between the three spatial traits but an inclination to interact as mutual cause and effect (Wang \& Zhao, 2016:18). Put another way, in Wang and Zhao's (2016) notes, in practice, the 'chunkiness', 'discreteness' and 'reversibility' turn out to be inseparably interwoven.

\subsection{Iconicity of Sequence/Order}

Currently, with a significant boost from functional and cognitive linguists, the notion of "iconicity" has prevailed over the "arbitrariness" that, despite overwhelming evidence to the contrary, traditionally is a seemingly immutable axiom. Opposed to the "arbitrariness" invoked by Saussure in his illustrious work Course in General Linguistics (1916), the launch of Jakobson's paper Quest for the Essence of Language $(1965,1971)$ appears to be a prelude to promising research prospect of the iconicity account. By way of eye-catching mention of the strong affinity between Peirce's semiotic concepts and research on grammar, this groundbreaking essay presents the first substantial challenge to the conventional dominance of "arbitrariness".

Peircean iconicity later is fervently advocated by Haiman (1980) who reduces Peircean typology to two varieties, that is, imagic iconicity and diagrammatic iconicity. The notion of diagrammatic iconicity, which is concerned with the structural/relational similarities between the sign and the referent, has been used in various functional and cognitive explanation of linguistic structure (cf. Jakobson, 1965, 1971; Plank, 1979; Haiman, 1980, 1984, 1985; Givón, 1985, 1991; Taylor, 2002; Haspelmath, 2008). In this paper, I only concentrate on a particular subtype of diagrammatical iconicity, that is, iconicity of sequence/order.

In Jakobson's reservoir of works, the allegedly iconicity of sequence/order can be explained by a chain of verbs "Veni, vidi, vici (I came, I saw, I conquered) (1971:350)", which inform us of that the word order of component clauses is employed to reproduce the sequence of a succession of reported events. This correspondence in sequence also finds its place in Greenberg's (1966:103) paper. He gives a relatively sophisticated account that "the order of elements in language parallels that in physical experience or that of knowledge".

A somewhat hackneyed but quintessential example from Greenberg $(1963,1966)$ is the all-but-universal precedence of subjects over objects, such that OSV, OVS, and VOS languages are a very rare occurrence. This dominant order in practice matches the sequence of experiences (i.e., it follows the order of AGENT-ACTION-PATIENT). Based upon such order, there is an unbridgeable gulf between SVO languages, such as English and Chinese, and SOV languages (or OV in spoken languages) like Japanese, giving effable evidence for the fact that "the degree of syntactic iconicity varies with languages" (e.g. Shen, 1993:4). To be exact, the SVO languages are found to be particularly prone to signal a higher degree of iconicity. Among scholars who bear out this averment ardently, a significant place belongs to Tai $(1985,1989)$, who reiterates that Chinese indicates a higher degree of iconicity than English. And, grounded on the evidences from contrastive studies, Chinse, English and Japanese make a concerted effort to show a gradual decline in the degree of iconicity (Wang, 1999:6).

Assiduously pursued by Givón (1991:92-93), two separate principles of natural sequential order used extensively in syntax are laid out.

\section{(3) Semantic principle of linear order:}

"The sequence of clauses in coherent discourse will tend to correspond to the temporal order of 
the occurrence of the depicted events".

(4) Pragmatic principle of linear order:

a. "More important or more urgent information tends to be placed first in the string".

b. "Less accessible or less predictable information tends to be placed first in the string".

The use of principle (3) is firstly reflected in the fact that the sequence of clauses is iconically motivated by the temporal sequence of events depicted in a connected discourse. For the principle (3), I have in mind such contrasting pairs (5a) and (5d) as follows:

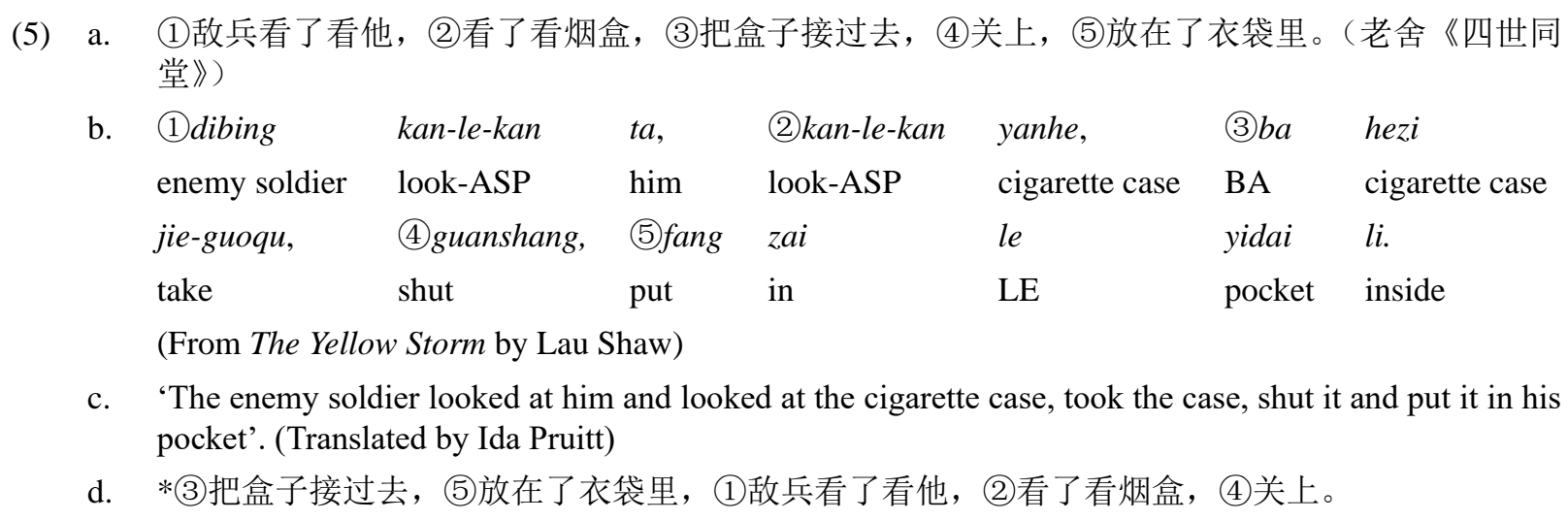

Another instance being often singled out is a near universality of the precedence of cause clauses over their paired effect clauses, and of condition clauses over their paired entailment clauses. Thus consider (Givón, 1991:92):

(6) Frequent: She shot him, and he died.

Infrequent: He died. She had shot her.

(7) Frequent: After she shot him, he died.

Infrequent: He died after she shot him.

The principle (4), in Givón's (1991:94) sentiments, can be condensed into an elegant statement that "unpredictable, less accessible, surprising information is likely to be more urgent than predictable, accessible information". In this sense, the string-initial or clause-initial positions tend to be reserved for less frequent, marked and new important information exposed by referents, that is, the "figure" (e.g. Langacker, 1991; Ungerer \& Schmid, 1996; Talmy, 2000), while the predictable and accessible information is always seen as the "ground" (e.g. Langacker, 1991; Ungerer \& Schmid, 1996; Talmy, 2000). Such "word order denoting the topicality of referents (Givón, 1991:93)" in terms of importance and accessibility can be detectable by the following topic constituents:

(8) a. Neutral: Chelsea really likes coffee.

b. Cleft-focused topic: It's coffee that Chelsea really likes.

c. Dangling topic: Coffee, Chelsea really likes it.

d. Contrastive topic: Chelsea really likes tea, but coffee she does not like.

\section{Further Discussion of Reversibility}

In this part, I will start with two cases, duyuju in CRS and shuncheng CRS, where 'reversibility' is instantiated to be ruled out. Then, pages will be devoted to a discussion of a cognitive mechanism, namely, the sequence/order principle, governing the clause order of CRS. Lastly, the present article will seek to lift the veil of the applicable scope of 'reversibility'.

\subsection{Duyuju in CRS}

Apropos of duyuju, the nominal independent sentence, Wang (2018) holds that it is a kind of non-subject-predicate structure in which nominal words or phrases are juxtaposed without an explicit grammatical connection and a verbal construct. In Wang's (2018) perspicacious attempt at a classification of duyuju, a noun or noun phrase can function as an independent sentence, a syntagm in CRS, or a juxtaposition of nouns or noun phrases separated by commas, as illustrated in example (9-11) below. 
(9) a. 笑声。同班同学的笑声。(1)天真无邪的笑声。(2)烂漫友善的笑声。

$\begin{array}{lllllll}\text { b. xiaosheng. } & \text { tongbantongxue } & d e & \text { xiaosheng. } & \text { (1)tianzhenwuxie de xiaosheng. } \\ \text { laughter } & \text { classfellow } & \mathrm{DE} & \text { laughter } & \text { naive } & \mathrm{DE} & \text { laughter } \\ \text { (2)langman } & \text { youshan } & d e & \text { xiaosheng. } & & & \\ \text { innocent } & \text { amicable } & \mathrm{DE} & \text { laughter } & & & \end{array}$

c. 'It is laughter; it is laughter of classfellow; it is naive laughter; it is innocent and amicable laughter'.

d. 笑声。同班同学的笑声。(2)烂漫友善的笑声。(1)天真无邪的笑声。

(10) a. 天色微明, 两个远远地见一簇人家, 看来是个村镇。两个投那村镇上来。(1)独木桥边, (2)一个 小小酒店。(施耐庵《水汻传》)

\begin{tabular}{|c|c|c|c|c|c|c|c|c|c|}
\hline tian & se & $w e i$ & ming, & & yиan & yиan & $d i$ & & $\begin{array}{l}y i-z u \\
\text { a-CL }\end{array}$ \\
\hline sky & color & slight & light & two-CL & & far & DI & see & $\mathrm{a}-\mathrm{CL}$ \\
\hline renjia, & kanlai & shi & ge & cunzhen. & liang-ge & tou & $n a$ & cunzhen & shang \\
\hline house & evidently & be & CL & town & two-CL & come & that & town & up \\
\hline lai. & (1)dumu & qiao & bian, & (2)yi-ge & $\underline{x i a o}$ & $\underline{x i a o}$ & jiudian. & & \\
\hline to & single-plank & bridge & side & $\mathrm{a}-\mathrm{CL}$ & small & small & tavern & & \\
\hline
\end{tabular}

(From Water Margin-by Shi Naian)

c. 'When the sky was turning light they saw a number of buildings in the distance, evidently a small town. Before long, they entered. They noticed a little tavern beside a single-plank bridge'. (Translated by J.M. Jackson)

d. 天色微明, 两个远远地见一簇人家, 看来是个村镇。两个投那村镇上来。先(2)一个小酒店, (1) 独木桥边。

a. (1)碧水, (2)蓝天, (3)青峰, (4)绿原。呵, (5)漓江, (6)一副迷人的画, (7)一条醉人的江。

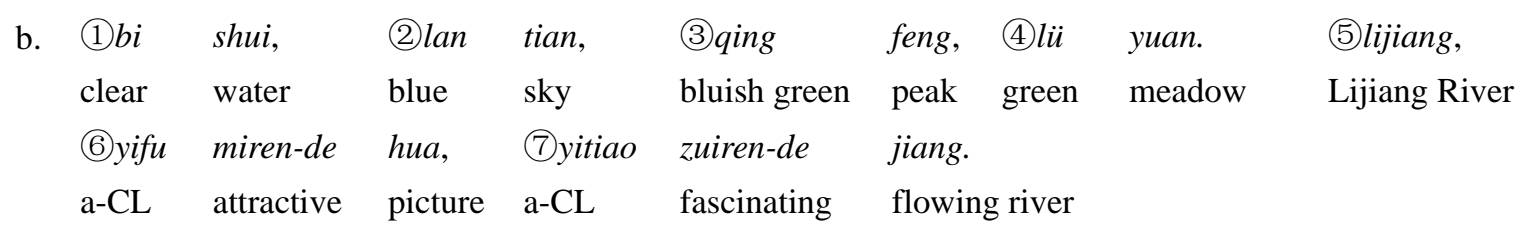

c. 'With the clear water, a blue sky, a bluish green mountain peak and a green meadow, the Lijiang River presents an attractive picture and a fascinating flowing river-'.

d. (2)蓝天, (4)绿原, (1)碧水, (3)青峰。呵, (5)漓江, (6)一条醉人的江, (7)一副迷人的画。

In example (9), a stream of nouns and nominal phrases, being independent, come together in a row, and then a "choppy sentence" "(Shen, 2012) generates. And (9d) shows that trading the place of syntagm (1) for the spot of (2) is allowed since there is a pure coordination between the two syntagms. Somewhat differently, a series of noun phrases (1) to (4) make up a CRS in example (11) where the syntagms (i.e. noun phrases), due to the coordinate relations among them, can be moved to different positions. Herein, my concern is not to discuss these two types of duyuju, but rather to dig deeper into the second type, namely, duyujus as syntagms in CRS.

The picture in example (10) where the underlined duyujus (/nominal independent sentences) serve as syntagms in CRS, is quite opposite to (9) and (11). To be specific, for one thing, in (10a), it is easy to determine that two nominal phrases are put side by side with no connective words to spell out their relationships. Wang and Liu (2021) explain that, owing to the preference for spatiality and the pursuit of aesthetic expressions, the linkage between the elements tends to be optional and redundant. For another thing, in Wang and Liu's (2021) deliberations, the juxtaposition of two nominal expressions in example (10a) is borne out to be closely germane to, and even equivalent to, the paratactic juxtaposition, that is, two images juxtaposed in spatial relations. It means that Wang, Zhao et al.'s (e.g. 2016) 'chunkiness' (/Shen's 'juxtaposition') embodies two layers of juxtaposition in CRS, that is, a juxtaposition of

${ }^{1}$ In Shen's (2012:412) notes, when the minor sentences (including noun phrases) become independent and are always separated by periods, the 'choppy sentence' arises. 
syntagms in structure and a juxtaposition of images in spatial relations. And the former juxtaposition always hinges on the latter. To be proper, in the underlined part in (10a), the sentence builder firstly presents the image of $a$ single-plank bridge, and then zooms in to focus on the tavern that is the place the subject(s) might head for. A picture can be vividly perceived: nearby there is a single-plank bridge, and by the bridge stands a small tavern. Therefore, following the sequence of visual representation in (10a), the order between syntagm (1) and (2) cannot be exchanged like example (10d).

Furthermore, by the same logic, the example (12a) below involving dujuyus as syntagms would be unacceptable if the series of nominal syntagms from (1) to (7) are rearranged in a different or reverse order, as (12d) showcased.

(12) a. ……扯他的衣襟与袖子要求他述说, 述说戏园中的奇双会, (1)枪声, (2)死亡, (3)椅子, (4)脑浆, (5)炸弹，(6)混乱，(7)伤亡…… (老舍《四世同堂》)

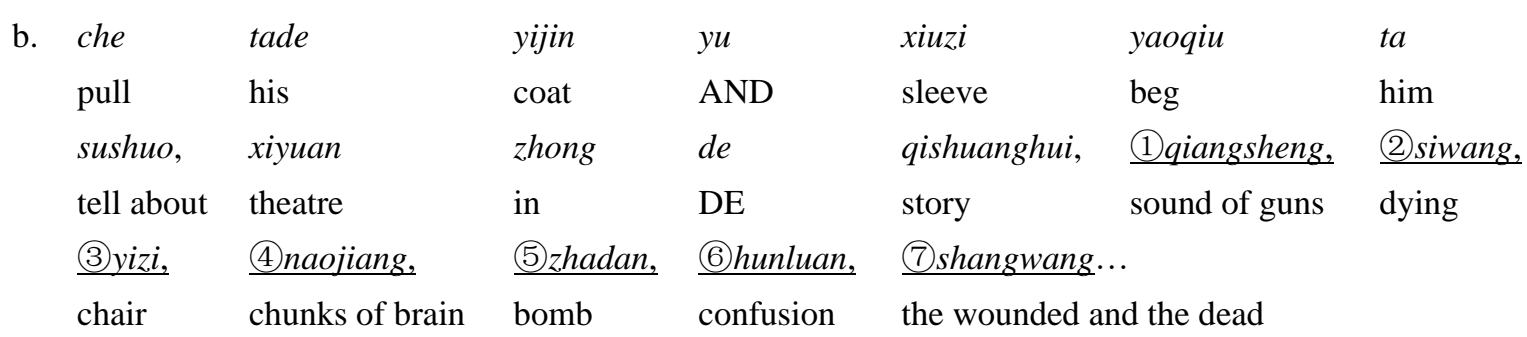
(From The Yellow Storm by Lau Shaw)

c. 'Fang the Sixth, of the Black Mole, had become the most important person. All surrounded him, pulled at his coat and his sleeves, and begged him to tell them the story-tell them about the sound of guns in the theatre, about the dying, the chair, about the chunks of brain, the bomb, the confusion, the wounded and the dead'. (Translated by Ida Pruitt)

d. *......扯他的衣襟与袖子要求他述说, 述说戏园中的奇双会, (2)死亡, (1)枪声，(3)椅子，(4)脑浆, (7)伤亡，(6)混乱，(5)炸弹…… (老舍《四世同堂》)

The unacceptability of (12d) comes down to the fact that the order of syntagm (1) to syntagm (7) are required to correspond to the temporal order of depicted occurrences. It means that the syntagm (1) to syntagm (7) turns out to be placed in a temporal order. Given the specific context, some audiences died after several gunshots, therefore the syntagms (1) and (2) fail to be transposed. The same is true for syntagms (5), (6) and (7), which jointly present a fast-moving succession of events. Perhaps, there is a distinct possibility that a sentence builder might exchange the position of syntagms (6) and (7) since a coordinate relation can be tracked down between them. However, albeit a remote chance, moving the syntagms (6) or (7) in front of the syntagm (5) cannot survive because it is easy to determine that hunluan (混乱 'chaos') and shangwang (伤亡 'injuries') are the consequences of bombs going off.

In view of the facts above, a problem ensues when the duyujus are put side by side by spatial relations in (10) and temporal relations in (12). To be exact, the aforesaid facts we have unearthed seem to directly contradict Wang and Zhao et al.'s (e.g. Wang \& Zhao, 2016, 2020; Wang \& Liu, 2021) 'reversibility', which gives its speakers unusual flexibility in moving and even reversing elements. Put another way, it seems that the 'reversibility' appears to be fast-fingered in examples (10) and (12).

However, I list some cases in (13-14), where duyujus also work as independent syntagms within CRS, appear to run counter to the situations in (10) and (12).

（13） a. (1)公园，(2)北海，(3)天坛，(4)万牲园，在星期日，完全是日本人的世界。(老舍《四世同堂》)

\begin{tabular}{|c|c|c|c|c|c|}
\hline $\begin{array}{l}\text { (1) gongyuan, } \\
\text { park }\end{array}$ & $\frac{\text { (2) beihai, }}{\text { the North Sea }}$ & $\begin{array}{l}\text { (3)tiantan, } \\
\text { the Temple of Heaven }\end{array}$ & $\begin{array}{l}\text { (4) wanshengyuan, } \\
\text { zoo }\end{array}$ & $\begin{array}{l}z a i \\
\text { on }\end{array}$ & $\begin{array}{l}\text { xingqiri, } \\
\text { Sunday }\end{array}$ \\
\hline wanquan & shi & ribenren & $d e$ & shijie. & \\
\hline entirely & $\mathrm{BE}$ & Japanese & $\mathrm{DE}$ & world & \\
\hline
\end{tabular}

(From The Yellow Storm by Lau Shaw)

c. 'All the parks, the North Sea and the Temple of Heaven, and the zoo were entirely Japanese worlds on Sundays'. (Translated by Ida Pruitt)

d. (4)万牲园，(2)北海，(3)天坛，(1)公园，在星期日，完全是日本人的世界。老舍《四世同堂》) 
（14） a. 中国，现在他才明白，有那么多不同的天气，(1)地势，(2)风俗，(3)方言，(4)物产…… (老舍《四 世同堂》)

$\begin{array}{llllllll}\text { b. } & \text { zhongguo, } & \text { xianzai } & \text { ta } & \text { cai } & \text { mingbai, } & \text { you } & \text { name-duo butongde } \\ \text { China } & \text { now } & \text { he } & \text { begin } & \text { understand } & \text { have } & \text { so many } & \text { different } \\ \text { tianqi, } & \underline{\text { (1) dishi, }} & \underline{\underline{(2) f e n g s u},} & \underline{\text { (3) fangyan, }} & \underline{\text { (4)wuchan }} & & & \\ \text { climate } & \text { land } & \text { custom } & \text { dialect } & \text { resource } & & & \end{array}$

(From The Yellow Storm by Lau Shaw)

c. 'China, he now began to understand, had many different climates, different kinds of land, different customs, different dialects and different resources'. (Translated by Ida Pruitt)

d. 中国，现在他才明白，有那么多不同的天气，(3)方言，(2)风俗，(1)地势，(4)物产…… (老舍《四 世同堂》)

Analogous to the syntagms (6) or (7) in example (12a), the syntagms (1) to (4) in (13a) and syntagms (1) to (4) in (14a) can also be moved and even reversed to other positions since both of them exhibit purely coordinate relations. In this sense, the 'reversibility' appears to be "welcome" at (13a) and (14a). To some extent, the difference between the present cases (13) and (14) and aforesaid cases (10) and (12) comes down to their different constructional environments. To be exact, clearly the 'reversibility' is given a cordial welcome by the former cases, but is shown as undesirable in the latter.

To wrap up, there is no dispute that it is not really the case as Wang et al.'s (e.g. Wang \& Zhao, 2016, 2017a, 2017b, 2020; Cui, 2017; Cui \& Wang, 2019; Wang \& Liu, 2021) 'reversibility' depicted. Albeit the removed and reversed duyuju syntagms exist indeed in CRS, there are some counterexamples where permission is denied to remove syntagms due to the spatial/temporal relations. However, admittedly, this kind of nuanced cases (10) and (12) involving duyujus as syntagms seem to not carry much conviction. So, we have better zero in on another case within CRS.

\subsection{Shuncheng Relations in CRS}

The linguists (e.g. Hu, 1984; Wang, 1994; Sheng, 2016) of the recent past have puzzled their brains about the multi-tiered relations among syntagms in CCS and have yielded fruitful results. For instance, four basic varieties, that is, coordinate relation, shuncheng relation, jieshuo/commentary relation and clausal relation, are gathered by Sheng (2016). The second type, shuncheng CRS, is a kind of sentence where the occurrences/actions depicted in preceding syntagms come before those in subsequent syntagms. It means that the sequence of linguistic forms in shuncheng CRS matches the actual order of experiences. Sentence (15), for example, is thought to be illustrative (Sheng, 2016).

(15) a. (1)出了屋门, (2)他仰头看看天, (3)天是那么晴朗美丽, (4)他知道自己还是在北平的青天底下。(老 舍《四世同堂》)

b. (1) chu-le

$\begin{array}{ll}\text { wumen, } & \text { (2) ta } \\ \text { door } & \text { he }\end{array}$

yangtou

$\begin{array}{llll}\text { kan-kan } & \text { tian, } & \text { (3)tian } & \text { shi } \\ \text { look at } & \text { sky } & \text { sky } & \text { BE } \\ \text { zhidao } & \text { ziji } & \text { haishi } & \text { zai } \\ \text { know } & \text { himself } & \text { still } & \text { in }\end{array}$

so

come out-ASP

door

he

lift the head

name

qinglang

meili,

(4) $t a$

beautiful he clear and bright

qing

dixia.

Peiping

DE

clear and blue sky

under

(From The Yellow Storm by Lau Shaw)

c. 'Coming out of the room he lifted his head to look at the sky - the sky so beautiful, so clear, so bright - and knew that he was still under the clear, blue skies of Peiping'. (Translated by Ida Pruitt)

d. *(3)天是那么晴朗美丽, (2)他仰头看看天, (1)出了屋门, (4)他知道自己还是在北平的青天底下。 (老舍《四世同堂》)

It is shown that the example (15d) is not felicitous as (15a) in logic owing to their distinction in the word order of syntagms. Specifically speaking, Intuitively, the actions described in syntagms (1), (2) and (3) occurred ahead of that in syntagm (4). Put another way, other things being equal, the order of statements, namely, syntagms (1) to (4), in a narrative description corresponds to the temporal order of the events they describe. In contrast, the temporal 
sequence presented in example (15d) goes against the time stream of the sentence builder's mind. Meanwhile, a big question-mark hangs over the logical relations among component clauses in (15d). Hence, the sentence (15d) in which the 'reversibility' is applied is left to be unacceptable.

Other than denoting temporal order like (15), to a large degree, the shuncheng CRS can also indicate the order of spatiality and logic. Let's tease it apart by considering following examples.

(16) a. (1)五间北房呢, (2)中间作客厅; (3)客厅里东西各有一个小门, (4)通到瑞宣与瑞丰的卧室; (5)尽东 头的和尽西头的一间, (6)都另开屋门, (7)东头是瑞全的, (8)西头是祁老太爷的卧室。

$\begin{array}{llllllll}\text { b. (1) wujian } & \text { bei } & \text { fang } & \text { ne, } & \text { (2) zhongjian } & \text { zuo } & \text { keting; } & \text { (3)keting } \\ \text { five-CL } & \text { north } & \text { room } & \mathrm{NE} & \text { middle } & \text { as } & \text { parlor } & \text { parlor } \\ l i & \text { dong } & x i & g e & \text { you } & \text { yi-ge } & \text { xiaomen, } & \text { (4)tongdao } \\ \text { in } & \text { east } & \text { west } & \text { each } & \text { have } & \text { one-CL } & \text { door } & \text { to } \\ \text { ruixuan } & y u & \text { ruifeng } & & \text { de } & \text { woshi; } & \text { (5)jindongtou } & \text { he } \\ \text { Rey Shuan(name) } & \text { AND } & \text { Rey Feng(name) } & \text { DE } & \text { bedroom } & \text { far east } & \text { AND } \\ \text { jinxitou } & d e & \text { yijian, } & \text { (6)dou } & \text { lingkai } & \text { wumen, } & \text { (7)dongtou } & \text { shi } \\ \text { far west } & \text { DE } & \text { one-CL } & \text { all } & \text { open } & \text { door } & \text { far east } & \text { SHI } \\ \text { ruiquan } & d e, & \text { (8xitou } & \text { shi } & \text { qilaotaiye } & d e & \text { woshi. } & \\ \text { Rey Tang(name) } & \text { DE } & \text { far west } & \mathrm{SHI} & \text { Old Man Chi } & \text { DE } & \text { bedroom } & \end{array}$

(From The Yellow Storm by Lau Shaw)

c. 'The middle room of the five in the north house was the parlor. East and west of the parlor were the bedrooms of Rey Shuan and Rey Feng. The rooms to the far east and the far west had each its own door into the court. The one on the east was Rey Tang's room and the one on the west was Old Man Chi's:'. (Translated by Ida Pruitt)

d. *(3)客厅里东西各有一个小门，(2)中间作客厅，(1)五间北房呢；(4)通到瑞宣与瑞丰的卧室，(3)客 厅里东西各有一个小门; (7)东头是瑞全的，(5)尽东头的和尽西头的一间，(8)西头是祁老太爷的卧 室，6都另开屋门。(老舍《四世同堂》)

In example (16a), a host of syntagms (/clauses or phrasal expressions) are arranged in a sequence of spatial relations underlying the sentence. From the syntagm (1) to (8), a series of images are presented one by one from the middle room of the five in the north house to the far east and far west. Slightly differently, there is a strong tendency in sentence (17a) below to order syntagms according to sequence of logic. All told, analogous to examples (15-16) (where temporal and spatial relations are involved), the CRS in (17a) also rules out the appearance of 'reversibility'.

(17) a. (1)他继续设想, (2)鸡又生鸡, (3)用鸡卖钱, (4)钱买母牛, (5)母牛繁殖, (6)卖牛得钱, (7)用钱放 债, 8这么一连串的发财计划, 9)当然也不能算是生产的计划。(马南邨《燕山夜话》)

b. (1) $t a$

he

$j i$

chicken

(6) mai

sell

(8) zheme

this

suanshi

considered as jixu

continue

mai

sell

niu

cow

yilianchuan

a link chain

shengchan

$\begin{array}{llllll}\text { shexiang, } & \text { (2ji } & \text { you } & \text { sheng } & \text { ji, } & \text { (3)yong } \\ \text { imagine } & \text { chicken } & \text { again } & \text { breed } & \text { chicken } & \text { use } \\ \text { qian, } & \text { (4)qian } & \text { mai } & \text { muniu, } & \text { (5)muniu } & \text { fanzhi, } \\ \text { money } & \text { money } & \text { buy } & \text { cow } & \text { cow } & \text { breed } \\ \text { de } & \text { qian, } & \text { (7)yong } & \text { qian } & \text { fang } & \text { zhai, } \\ \text { earn } & \text { money } & \text { use } & \text { money } & \text { provide } & \text { loan } \\ \text { de } & \text { facai } & \text { jihua, } & \text { 9)dangran } & \text { ye } & \text { buneng } \\ \text { DE } & \text { rich } & \text { plan } & \text { of course } & \text { also } & \text { connot }\end{array}$

(From Evening Talks at Yanshan by Ma Nancun)

c. 'The cows would breed too, and selling cows would make more money for him. With the money, he could become a money lender. Such a succession of steps of getting rich, of course, had nothing at all 
to do with production'.

d. *(3)用鸡卖钱, (2)鸡又生鸡, (4)钱买母牛, (9)当然也不能算是生产的计划, (1)他继续设想, (5)母 牛繁殖, (7)用钱放债, (6)卖牛得钱, 8这么一连串的发财计划。(马南邨《燕山夜话》)

Sheng (2016), with zeal and genius, unveils the secrets of the word order of syntagms in shuncheng CRS. In Sheng's (2016) shrewd cognizance, the order of linguistic forms in shuncheng CRS tends to be stereotyped. Put slightly differently, due to this kind of fixed sequence, the syntagms in shuncheng CRS cannot be removed or reversed. Furthermore, the sequence of linguistic forms always mirrors the spatial/temporal/logical sequence of actions/events depicted in shuncheng CRS (Sheng, 2016:87). If, in shuncheng CRS, some removements or inversions of syntagms surface, the conventional logical relations among them would be wrecked and the word order would run counter to the sequence of experiences (Sheng, 2016:87). All in all, to the best of my present analysis, a mini-conclusion can be arrived at is that the contention of Wang et al.'s (e.g. Wang \& Zhao, 2016, 2020; Wang \& Liu, 2021) 'reversibility' also appears to be excluded in shuncheng CRS, as examples (15-17) illustrated.

Something also to note is that the unacceptability of 'reversibility' is not absolutely in shencheng CRS. Put another way, Sheng (2016:87) adds that sometimes this kind of CRS may be well-formed even under the condition that the positions of some clauses undergo (huge) shifts (see examples (18-19) below).

(18) a. (1)他揪着自己的裤腿蹲下去, (2)含笑低头。

$\begin{array}{lllllll}\text { b. (1) ta jiuzhe } & \text { zijide } & \text { kutui } & \text { dunxiaqu, } & \text { (2)hanxiao } & \text { ditou. } \\ \text { he tug } & \text { his } & \text { pant leg } & \text { crouch down } & \text { with a smile } & \text { lower one's head }\end{array}$

c. 'He tugged his pant leg, crouched down and looked down with a smile'.

d. 他(2)含笑低头, (1)揪着自己的裤腿蹲下去。

(19) a. (1)老师皱了一下眉, (2)没有言语, (3)低头改作业。

b. (1)laoshi zhou-le yixia mei, (2)meiyou yanyu, (3)ditou gai zuoye. teacher furrow-ASP one-CL brow no words look down grade homework

c. 'The teacher furrowed his brow, and looked down at the homework without any words'.

d. 老师(3)低头改作业，(2)没有言语，(1)皱了一下眉。

Clearly, the sentences in examples (18d) and (19d) are both intuitively correct and make sense in logic, even though the syntagms (1) and (2) in (18a) and the syntagms (1), (2) and (3) in (19a) undergo the 'reversibility'. Nonetheless, Sheng (2016:88) constructively holds that this kind of rearrangement in (18d) and (19d) would lead to a shift of their semantic relations compared with the word order of original sentences (18a) and (19a). In other words, at first sight, Wang et al.'s (e.g. Wang \& Zhao, 2016, 2017a, 2020; Wang \& Liu, 2021) 'reversibility' seems to be accepted in shuncheng CRS sometimes, but the semantic/logical relations among synatgms would experience some (huge) shifts. Therefore, we might as well address the elephant in the room rather than temporarily leave aside the differences between (18a-19a) and (18d-19d).

In a nutshell, shuncheng CRS, as an indicator of temporal/spatial/logical relations, to some extent can serve as a sort of filler and a way of suggesting that, in practice, the 'reversibility' fails to work in some cases of CRS. It should be pointed out that shuncheng CRS holds a majority in the family of CRS. Therefore, together with the cases of duyujus in CRS, it is well-founded to call into question the rationale of 'reversibility'. To be more exact, based upon our observation of duyujus in CRS and shuncheng CRS, Wang et al.'s (e.g. Wang \& Zhao, 2016, 2017a, 2017c, 2020; Wang \& Liu, 2021) 'reversibility' in fact is borne out to be a local or partial property rather than near-universal. The knotty problem here is that, in the words of Wang and Zhao et al. (e.g. 2016, 2020), the existence of 'reversibility', which in theory has the same status as the other two traits, 'chunkiness' and 'discreteness', should have been universally recognized in CRS in practice. Put another way, the 'reversibility' has to showcase a near universality and should be able to work in all types of CRS and all sorts of syntagms in CRS. And all syntagms in all varieties of CRS can be removed and even reversed to other positions. In short, the ideal universality of 'reversibility' in CRS is demonstrated to be totally at variance with the evidences presented in this article.

\subsection{Sequential Order Principles on Clause Order}

Up to now, we have arrived at a tentative conclusion that there exist some linguistic environments, namely, duyujus in CRS and shuncheng CRS, where the 'reversibility' is deemed as an "unexpected visitor". Under our analysis, what we have revealed with regard to the application of 'reversibility', as examples (10), (12), and (15-17) displayed, is 
presumably motivated by the same cognitive factor, that is, the iconicity of sequence/order (Haiman, 1980, 1984, 1985; Jakobson, 1965, 1971; Tai, 1985, 1989; Givón, 1991; Shen, 1993) that to a large degree rules out the use of 'reversibility' in CRS.

Apropos of the iconicity of sequence/order, it is one of the widely accepted motivating principles subsumed under the broad heading of iconicity. Previous research endeavors (e.g. Haiman, 1980, 1984, 1985; Tai, 1985, 1989; Givón, 1991) pertinent to the definition of this principle can be encapsulated as follow: the sequence of component clauses or linguistic forms in connected discourse is iconically motivated by, or corresponds to, the sequence of the narrated occurrences in conceptual world.

\subsubsection{The Principle of Temporal Sequence}

According to the 'semantic principle of linear order' given by Haiman (1980), and the 'Principle of Temporal Sequence (PTS)' by Tai (1985:50), "the relative word order between two syntactic units is determined by the temporal order of the states which they represent in the conceptual world". In view of this, the unacceptability of examples like (12d), (15d), (16d) and (17d) can be predicted. Accordingly, the 'reversibility' turns out to be unable to work in these sentences. Another representative example (20) below can also be adduced. a. (1) 我
中。

b. (1)wo

悄地起身,

(2)穿上大衣,

(3)轻轻地带上门,

(4)蹑手蹑脚地走了出去,

(5)消失在茫茫夜色

$$
\text { I }
$$

qiaoqiaode

qishen,

(2) chuanshang

dayi, nieshouniejiaode

rise up

put on

overcoat

qingqingde

daishang

xiaoshi

carefully

close

men, stealthily

zou-le chuqu,

disappear in

yese

zhong.

c. 'I rose up noiselessly, put on my overcoat, closed the door carefully, went out stealthily and melted into the night'.

d. *(3)轻轻地带上门, (4)蹑手蹑脚地走了出去, (2)穿上大衣, (5)消失在茫茫夜色中, (1)我悄悄地起
身。

In the case of (20), following Haiman's (e.g. 1980, 1984, 1985) line of thinking, if we place the syntagm (1) to the wake position, it would go against the order of a series of occurrences and actions in conceptual world. In light of the 'semantic principle of linear order' and 'principle of temporal sequence (PTS)', the actions pinpointed by a succession of predicates that firstly take place should ideally be described firstly, and those happen at a later time should also come next in the sentence. However, the example (20d) adduced here that involves the 'reversibility' goes in the opposite direction of the ideal case brought light on by Haiman (1980, 1984, 1985) and Givón (1991). Therefore, that is the reason why 'reversibility' is proved ill-suited in examples listed in this article.

\subsubsection{The Principle of Spatial Sequence}

As well as following Haiman et al.'s (e.g. 1980, 1984, 1985) statements, the "Principle of Spatial Sequence (PSS)" can provide a convincing account for the disuse of 'reversibility' in examples (10) and (16). This kind of principle underlines that the spatial sequence of constructing linguistics forms matches their spatial perception about the world. Hence, there is a strong tendency of sentence builders to order syntagms according to a certain kind of convention. In Liu's (2006) notes, spatial sequence, just like the temporal sequence, tends to arrange syntagms based on the size, the width, and the distance of space. And the order of depicting some images with spatial relations is constrained by body experience and mainly rests on the visual perception. Conventionally, Chinese speakers would rather to express spatiality in a way from nearness to farness. That is to say, dependent on the point of visual perception, sometimes the nearer image may be deemed as the "figure" (e.g. Langacker, 1991; Ungerer \& Schmid, 1996; Talmy, 2000), and the farther image appears to be less salient and thus is the "ground" (e.g. Langacker, 1991; Ungerer \& Schmid, 1996; Talmy, 2000). Other than that, other principles of spatial sequence like same-direction principle also exist (Sheng, 2016:68). I have in mind an example as the following:

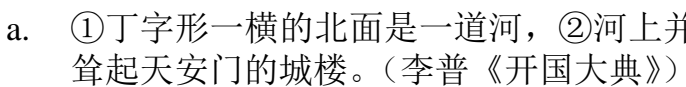
b. (1)dingzixing-yiheng de
T-shaped
shang
$\mathrm{DE}$
bingpai

beimian
north
zhe
shi
SHI
wu-zuo
$\begin{array}{ll}\text { yi-dao } & \text { he, } \\ \text { one-CL } & \text { river } \\ \text { bai } & \text { shiqiao; }\end{array}$
(2)he
river
(3) zai 


$\begin{array}{llllll}\text { on } & \text { stand side by side } & \text { ASP } & \text { five-CL white } & \text { stone bridge } & \text { further } \\ \text { beimian } & \text { shi } & \text { chengqiang, } & \text { (4)chengqiang } & \text { zhongyang } & \text { gaogao } \\ \text { north } & \text { SHI } & \text { rampart } & \text { rampart } & \text { center } & \text { high } \\ \text { songqi } & \text { tiananmen } & d e & \text { chenglou. } & & \\ \text { rise } & \text { the Gate of Heavenly Peace } & \text { DE } & \text { rampart } & & \end{array}$

(From Founding Ceremony by Li Pu)

c. 'To the north of the T-shaped one is a river with five white stone bridges standing side by side on the river; to the further north is the rampart, in the center of which the tower of the Gate of Heavenly Peace rises'.

d. *(3)再北面是城墙, (1)丁字形一横的北面是一道河, (4)城墙中央高高算起天安门的城楼, (2)河上并 排架着五座白石桥。(李普《开国大典》)

In (21), the sentence builder, with an inclination to express images in a way from nearness to farness, presents the river firstly and then depicts a picture of wu-zuo bai shiqiao 'five white stone bridges', chengqiang 'the rampart', Tiananmen 'the tower of the Gate of Heavenly Peace' successively.

All told, although Wang, Zhao et al.'s (e.g. Wang \& Zhao, 2016, 2020; Wang \& Liu, 2021) analysis of 'reversibility' seems appealing, the problem that it has to come to grips with is that 'reversibility' is expected to work in all sorts of CRS, but instead is demonstrated as not simply random without rules. Namely, so far at least, the duyujus in CRS and shuncheng CRS alike refuse to accept Wang et al.'s (e.g. Wang \& Zhao, 2016) insistence of 'reversibility'. Also, one cannot give a cold shoulder to some cognitive principles, such as the principle of spatial sequence, the principle of temporal sequence and same-direction principle (Sheng, 2016), under the label of the iconicity of sequence/order (e.g. Haiman, 1980, 1984, 1985) governing the clause order of CRS. Namely, although the 'reversibility' sometimes exhibits a tendency to change the word order of syntagms in CRS, there is a clear correlation between the clause order of CRS and iconicity account. In this sense, CRS is borne out to be not an exception to the iconicity of sequence/order.

\subsection{Constraints on Reversibility}

To the best of the present analysis, we have revealed that the 'reversibility' fails to be used at random in all sorts of CRS. Namely, the application of 'reversibility' has some limitations, which cannot get short shrift. Under our analysis, a condition that can rule out the application of 'reversibility' is called Reversibility Filter Condition:

\section{(22) The Reversibility Filter Condition}

The 'reversibility' will be ruled out under the condition that:

i. There exist some temporal/spatial relations among syntagms; or

ii. There exist some certain logical relations among syntagms.

Analogously, some typical constructional environments where the 'reversibility' can be licensed can be further encapsulated as Reversibility Condition:

\section{(23) The Reversibility Condition}

The 'reversibility' can be licensed if and only if:

i. There exist purely coordinate relations but no temporal/spatial relation among syntagms; or

ii. There exist certain cause-effect relations among syntagms; or

iii. There exist certain condition-entailment relations among syntagms.

We can think of this condition as being like a driver's license. Only when we get a license at the Department of Motor Vehicles, can we drive. Therefore, we have to go there to get the license. The same is true for Wang et al.'s (e.g. Wang \& Zhao, 2016, 2017a, 2017b, 2020) 'reversibility' that needs a license to be able to surface in CRS. The Reversibility Condition herein is required to serves as a license for the occurrence of 'reversibility' in CRS. If 'reversibility' appears in some cases beyond the Reversibility Condition listed above or has some intolerable dissociations from the core cases enumerated in the Reversibility Condition, the 'reversibility' would be incapable of "driving" without license. In short, the Reversibility Condition in practice becomes a requirement that 'reversibility' can succeed being applied in CRS. Therefore, such requirement stipulated in (23) can be invoked to account for the 
fact shown in (24) (repeating (13) above) that involves a pure coordination among the underlined syntagms, gongyuan 'park', beihai 'the North Sea', tiantan 'the Temple of Heaven' and wanshengyuan 'zoo'. Since the example (24) is able to satisfy the Reversibility Condition, the positions of syntagms from (1) to (4) can be interchanged and even reversed.

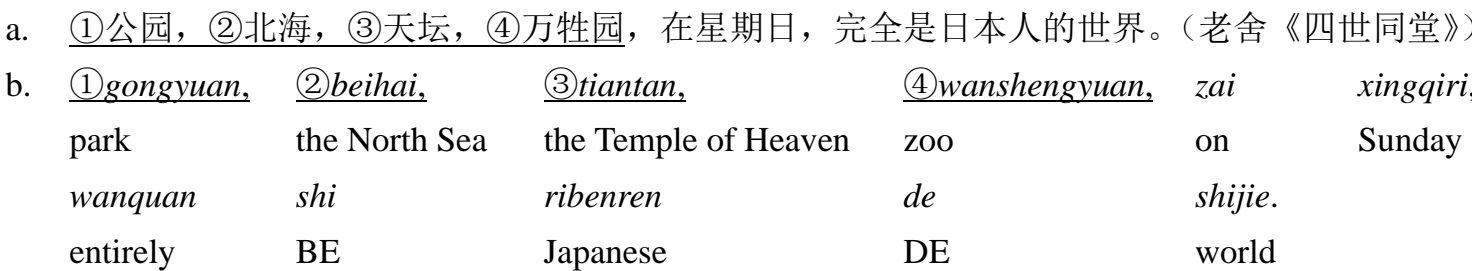

(From The Yellow Storm by Lau Shaw)

c. 'All the parks, the North Sea and the Temple of Heaven, and the zoo were entirely Japanese worlds on Sundays'. (Translated by Ida Pruitt)

d. (4)万牲园, (2)北海, (3)天坛, (1)公园, 在星期日, 完全是日本人的世界。老舍《四世同堂》)

Furthermore, to some extent, the Reversibility Filter Condition and Reversibility Condition alike have demonstrated that Wang and Zhao's (e.g. 2016) 'reversibility' is merely a local property rather than a general or overall one. The reason why the clause order in CRS sometimes appears to be not fixed and even some reversed phenomena can surface are precisely because, on the one hand, some syntagms of CRS are in certain cause-effect and condition-entailment relationships, by virtue of which new orders such as "effect-cause" and "entailment-condition" ensue. On the other hand, if there is a pure coordination in CRS, there would be no dispute that the appearance of removed and reversed syntagms is allowed.

\section{Conclusion}

In this study, the present author does not deal with all three traits of Wang, Zhao et al.'s (Wang \& Zhao, 2016, 2017a, 2017b, 2017c, 2020; Cui, 2017; Cui \& Wang, 2019; Wang \& Liu, 2021) spatiality of CRS, such as 'chunkiness' and 'discreteness'; rather, I attend to a further discussion of 'reversibility' and an attempt at oppugning the rationale of 'reversibility' has been made.

On the whole, based upon the facts of duyujus in CRS and shuncheng CRS, it is argued here that, in most cases, the composition of CRS is still governed by the "iconicity of sequence/order" (e.g. Haiman, 1980, 1984, 1985), which generates the Reversibility Filter Condition in (22). Nonetheless, the 'reversibility' is also proved to be desirable in some scenarios listed in the Reversibility Condition (23). Given that, the present analysis has revealed that the 'reversibility' turns out to have no same near universality as other spatial traits, namely, 'chunkiness' and 'discreteness', but instead to be bound by the Reversibility Filter Condition (22). In view of that, two summings-up can be further reached. For one thing, the arguments of Wang et al. (e.g. Wang \& Zhao, 2016, 2020; Cui \& Wang, 2019; Wang \& Liu, 2021) with regard to 'reversibility', as a defining property of CRS, seems to be unable to hold water. When the 'reversibility' is borne out to be not peculiar to all types of syntagms (e.g. duyuju as syntagm) and all varieties of CRS (e.g. shuncheng CRS), we suggest that the spatiality of CRS should be ameliorated as two traits, that is, 'chunkiness' and 'discreteness'. For another thing, notwithstanding some exceptions wrapped up in (23), CRS has been demonstrated to be not an exception of the "iconicity of sequence/order" (e.g. Haiman, 1980, 1984, 1985). On the contrary, most of the time, the composition and clause order of CRS is iconically motivated by the temporal/spatial order in conceptual world. Therefore, CRS, "as a mirror of Mandarin Chinese" (Wu \& Liang, 1992:316), together with other Chinese sentences, emerges to be a kind of iconicity-prominent sentence/utterance.

In spite of the major conclusions above, this article is far from an extensive paper with some limitations. Firstly, the cause-effect relation and condition-entailment relation in the Reversibility Condition (23) are left unaccounted for. Secondly, we believe that, besides the duyuju syntagm in CRS and shuncheng CRS, there must be other linguistic evidences for the unacceptability of 'reversibility' waiting to be presented in future studies. Thirdly, the constraints in the Reversibility Filter Condition (22) and applicable possibilities listed in the Reversibility Condition (23) maybe have not been exhausted. Lastly, the present author has merely taken the "iconicity of sequence/order" into consideration. Perhaps, there also exist other cognitive mechanisms for the use of 'reversibility'.

\section{Acknowledgements}

I gratefully acknowledge Prof. Cao Daogen, who gives me great help by providing me with the presentation of topic and inspiration of new ideas during the research. 


\section{References}

Chao, Y. R. (1968). A Grammar of Spoken Chinese. Berkley: University of California Press.

Cui, L. (2017). A Contrastive Study of the Spatial and Temporal Differences Between Chinese and English Syntactic Structures-Based on Chinese Run-on Sentences and their English Translation (Master Thesis). Beijing, China: Beijing Foreign Studies University.

Cui, L., \& Wang, W. B. (2019). The Reclassification of Chinese Run-on Sentence. Journal of PLA University of Foreign Languages, (4), 94-102.

Gao, G. S. (1988). “Changju” fenxi (Issues on Chinese Changju Analyses). Beijing, China: China Social Sciences Press.

Givón, T. (1985). Iconicity, isomorphism and nonarbitrary coding in syntax. In Haiman, J. (Ed.), Iconicity in Syntax. Amsterdam: John Benjamins Publishing Company, 187-219. https://doi.org/10.1075/tsl.6.10giv

Givón, T. (1991). Isomorphism in the grammatical code: Cognitive and biological considerations. Studies in Language, 15(1), 85-114. https://doi.org/10.1075/sl.15.1.04giv

Greenberg, J. (1963[1966]). Some universals of grammar with particular reference to the order of meaningful elements. In Greenberg, J. (Ed.), Universals of Language. Cambridge, MA: the MIT Press, 73-113.

Guo, S. L. (2004). The decisive factor of negative scope in Chinese singular-topic paratactic sentences. Journal of Fujian Normal University, (2), 96-103. https://doi.org/10.3969/j.issn.1000-5285.2004.02.018

Haiman, J. (1980). The iconicity of grammar: Isomorphism and motivation. Language, (56), 515-540. https://doi.org/10.2307/414448

Haiman, J. (1984). Natural Syntax: Iconicity and Erosion. Cambridge: Cambridge University Press.

Haiman, J. (1985). Iconicity in Syntax. Amsterdam: John Benjamins Publishing Company. https://doi.org/10.1075/tsl.6

Haspelmath, M. (2008). Frequency vs. Iconicity in explaining grammatical asymmetries. Cognitive Linguistics, 19(1), 1-33. https://doi.org/10.1515/cog.2008.001

Hu, M. Y., \& Jin, S. (1989). Liushuiju chutan (A research on Chinese run-on sentences). Foreign Language Teaching and Research, (4), 42-54. https://doi.org/cnki:sun:yyjx.0.1989-04-003

Hu, M. Y. (1984). "Laoqida" fuju jushi (Issues on the Complex Sentences in Lao Qi Da). Linguistic Research, (8), 35-40. https://doi.org/cnki:sun:ywyj.0.1984-03-004

Jakobson, R. (1965). Quest for the essence of language. Diogenes, 51(13), 21-37. https://doi.org/10.1177/039219216501305103

Jakobson, R. (1971). Quest for the essence of language. In Jakobson, R. (Ed.), Selected Writings (Vol. II). The Hague: Mouton, 260-266. https://doi.org/10.1515/9783110873269.345

Kong, X. Z. (1997). Problems in the Chinese Language: An Anthology. Hong Kong, China: The Commercial Press.

Langacker, R. W. (1991). Foundations of Cognitive Grammar (Vol. I). Stanford: Stanford University Press.

Lian, S. N. (1992). Lun yinghan jufa de jiben texing (Issues on basic features of English and Chinese syntax). Journal of Xiamen University, (3), 122-126.

Lian, S. N. (1993). Contrastive Studies of English and Chinese. Beijing, China: Higher Education Press.

Liu, M. Q. (2006). Chinese-English Contrastive Studies and Translation. Beijing, China: China Translation \& Publishing Corporation.

Lü, S. X. (1979). Issues on Chinese Grammatical Analyses. Beijing, China: The Commercial Press.

Plank, F. (1979). Ikonisierung und De-Ikonisierung als Prinzipien des Sprachwandels. Sprachwissenschaft, 4(2), 121-158.

Saussure, F. de. (1916). Course in General Linguistics. New York: Columbia University Press.

Shen, J. X. (1993). A survey of studies of iconicity in syntax. Foreign Language Teaching and Research, (1), 2-8.

Shen, J. X. (2012). On minor sentences and flowing sentences in Chinese: In commemoration of the $120^{\text {th }}$ birthday of Yuen Ren Chao. Studies of the Chinese Language, (5), 403-415. 
Shen, X. L. (2004). The Category System of Chinese Cultural Linguistics. Journal of Hangzhou Normal College, (3), 63-69. https://doi.org/10.3969/j.issn.1674-2338.2004.03.013

Sheng, L. C. (2016). The Study of Flowing Sentences in Modern Chinese (Ph.D. Thesis). Changchun, China: Jilin University.

Tai, J. (1985). Temporal sequence and Chinese word order. In Haiman, J. (Ed.), Iconicity in Syntax. Amsterdam: John Benjamins Publishing Company, 49-72. https://doi.org/10.1075/tsl.6.04tai

Tai, J. (1989). Toward a cognition-based functional grammar of Chinese. In Tai, J. \& Hsueh. F., (Eds.), Functionalism and Chinese Grammar. South Orange: Chinese Language Teachers Association, 187.

Talmy, L. (2000). Towards a Cognitive Semantics (Vol. I). Cambridge, MA: MIT Press. https://doi.org/10.7551/mitpress/6848.001.0001

Taylor, J. (2002). Cognitive Grammar. Oxford: Oxford University Press.

Ungerer, F. H., \& Schmid, H. J. (1996). An Introduction to Cognitive Linguistics. London \& New York: Longman.

Wang, W. B. (2018). Approaching the spatial trait in Chinese: Evidence from the presence of nominal independent clauses. Contemporary Rhetoric, (2), 44-54. https://doi.org/10.16027/j.cnki.cn31-2043/h.2018.02.005

Wang, W. B., \& Liu, X. M. (2021). Spatiality and temporality: The fundamental difference between Chinese and English. Langue, 251, 103011. https://doi.org/10.1016/j.lingua.2020.103011

Wang, W. B., \& Zhao, C. Y. (2016). Spatial traits of Chinese run-on sentences. Foreign Languages Research, (4), 17-21. https://doi.org/10.13978/j.cnki.wyyj.2016.04.004

Wang, W. B., \& Zhao, C. Y. (2017a). On the syntactic categorization of Chinese run-on sentences. Chinese Teaching in The World, (2), 171-179. https://doi.org/10.13724/j.cnki.ctiw.2017.02.002.

Wang, W. B., \& Zhao, C. Y. (2017b). Zhongguo xuexizhe chanchu yingyu "liushuiju" xianxiang pouxi: yinghan shikong chayi shijiao (A research on "run-on sentences" made by Chinese learners-Based on the difference of temporality in English and spatiality in Chinese). Foreign Language World, (1), 30-37. https://doi.org/10.1088/1475-7516/2017/01/005

Wang, W. B., \& Zhao, C. Y. (2017c). The classification of Chinese run-on sentence. Contemporary Rhetoric, (1), 35-43. https://doi.org/10.16027/j.cnki.cn31-2043/h.2017.01.004

Wang, W. B., \& Zhao, C. Y. (2020). Hanyu liushuiju yu yingyu fuzaju jiegou texing duibi: yinghan shikong chayi shijiao (On the structural contrast between Chinese run-on sentences and English complex sentence-Based on the difference of temporality in English and spatiality in Chinese). Foreign Language Education, (5), 27-32. https://doi.org/10.16362/j.cnki.cn61-1023/h.2020.05.006

Wang, W. X., Zhang, X. C., Lu, M. Y., \& Cheng, H. Y. (1994). Xiandai hanyu fuju xinjie (New Accounts of Modern Chinese Complex Sentences). Shanghai, China: East China Normal University Press.

Wang, Y. (1999). Iconicity of linguistic symbols. Foreign Languages and Their Teaching, (5), 4-7. https://doi.org/cnki:sun:wywj.0.1999-05-000

Wu, J. C., \& Liang, B. S. (1992). Xiandai hanyu jufa jiegou yu fenxi (Issues on Chinese Syntactic Structure and Analyses). Beijing, China: Yu Wen Publishing Company.

Yuan, Y. L. (2000). The scope ambiguity of negation in Chinese paratactic sentences. Chinese Teaching in The World, (3), 22-33. https://doi.org/cnki:sun:sjhy.0.2000-03-003

Zhang, B. (2000). Xiandai hanyu yufa fenxi (Issues on Modern Chinese Grammatical Analyses). Shanghai, China: East China Normal University Press.

Zhang, Y. Y. (2015). Research on the Coherence Mechanism of Chinese Run-on Sentence (Master Thesis). Nanjing, China: Nanjing University.

\section{Copyrights}

Copyright for this article is retained by the author(s), with first publication rights granted to the journal.

This is an open-access article distributed under the terms and conditions of the Creative Commons Attribution license (http://creativecommons.org/licenses/by/4.0/). 